\title{
Research on Quality Diagnosis and Improvement Strategy of Practice Teaching in Higher Vocational Colleges
}

\author{
Zhuang Li \\ Changzhou College of Information Technology, Jiangsu, China, 213164
}

Keywords: higher vocational colleges; classroom teaching quality; diagnosis and improvement mechanism

\begin{abstract}
In order to improve the level of talent training and maintain a strong vitality and core competitiveness in higher vocational education, higher vocational colleges must establish a diagnostic and improvement mechanism for classroom teaching quality. The diagnosis and improvement of classroom teaching quality in higher vocational colleges is a work process for the insufficiency of the search for the quality of classroom teaching in the higher vocational colleges and the improvement of the quality of classroom teaching. Higher vocational colleges should establish a normalized periodic classroom teaching diagnosis and improvement mechanism based on self-diagnosis and external diagnosis and set up an expert committee to fully preside over the diagnosis and improvement work, through teachers, management departments, departments (departments), supervising, students' diagnosis of teachers' classroom teaching effects and teaching process, helping teachers to establish a normalized periodic self-diagnosis mechanism and promoting the continuous improvement and development of teachers' teaching ability.
\end{abstract}

1. Connotation of quality diagnosis and improvement of classroom teaching in higher vocational colleges

The diagnosis and improvement of classroom teaching quality in higher vocational colleges is an important factor in the training of talents in higher vocational colleges. The insufficiency of classroom teaching quality and the improvement and improvement of the work process. The specific contents include: setting up a committee of classroom teaching quality diagnosis and improvement, establishing a normalized periodic classroom teaching diagnosis and improvement working mechanism based on self-diagnosis and external diagnosis, through self-diagnosis, management department diagnosis, supervision diagnosis, peer diagnosis , student diagnosis, expert diagnosis, third-party diagnosis and other types of diagnosis methods, to diagnose classroom teaching results and teaching status and ultimately help teachers analyze problems in classroom teaching, form diagnostic reports, feedback improvement suggestions and guidance, Encourage and urge teachers to continuously improve the quality of classroom teaching ${ }^{[1]}$. 
2. The necessity of establishing quality diagnosis and improvement mechanism for classroom teaching in higher vocational colleges

2.1. Establishing a classroom teaching quality diagnosis and improvement mechanism is a requirement for implementing the national education policy

The Notice of the General Office of the Ministry of Education on Establishing a System for Diagnosing and Improving the Teaching Work of Vocational Colleges (Faculty and Staff Office [2015] No. 2) clearly requires that, starting from the fall of 2015, gradually establish a teaching diagnosis in vocational colleges across the country. c Improve the system and comprehensively carry out teaching diagnosis and improvement work1. Classroom teaching is an important part of the teaching work in higher vocational colleges. The overall construction of teaching work diagnosis and improvement work mechanism in higher vocational colleges must establish a diagnostic and improvement mechanism for classroom teaching quality ${ }^{[2]}$.

2.2. Establishing the diagnosis and improvement mechanism of classroom teaching quality is the inherent requirement of self-improvement of internal quality assurance system in higher vocational education

The quality of higher vocational education must be continuously improved and improved. It is necessary to analyze the classroom teaching situation regularly, find out the existing problems, analyze the causes of the problems, explore the improvement measures and establish a long-term teaching quality diagnosis and improvement mechanism. This mechanism is run to ensure that the quality of classroom teaching is continuously improved and improved ${ }^{[3]}$. The growth of the number of fresh graduates in higher vocational colleges is extremely rapid, as shown in Figure 1.

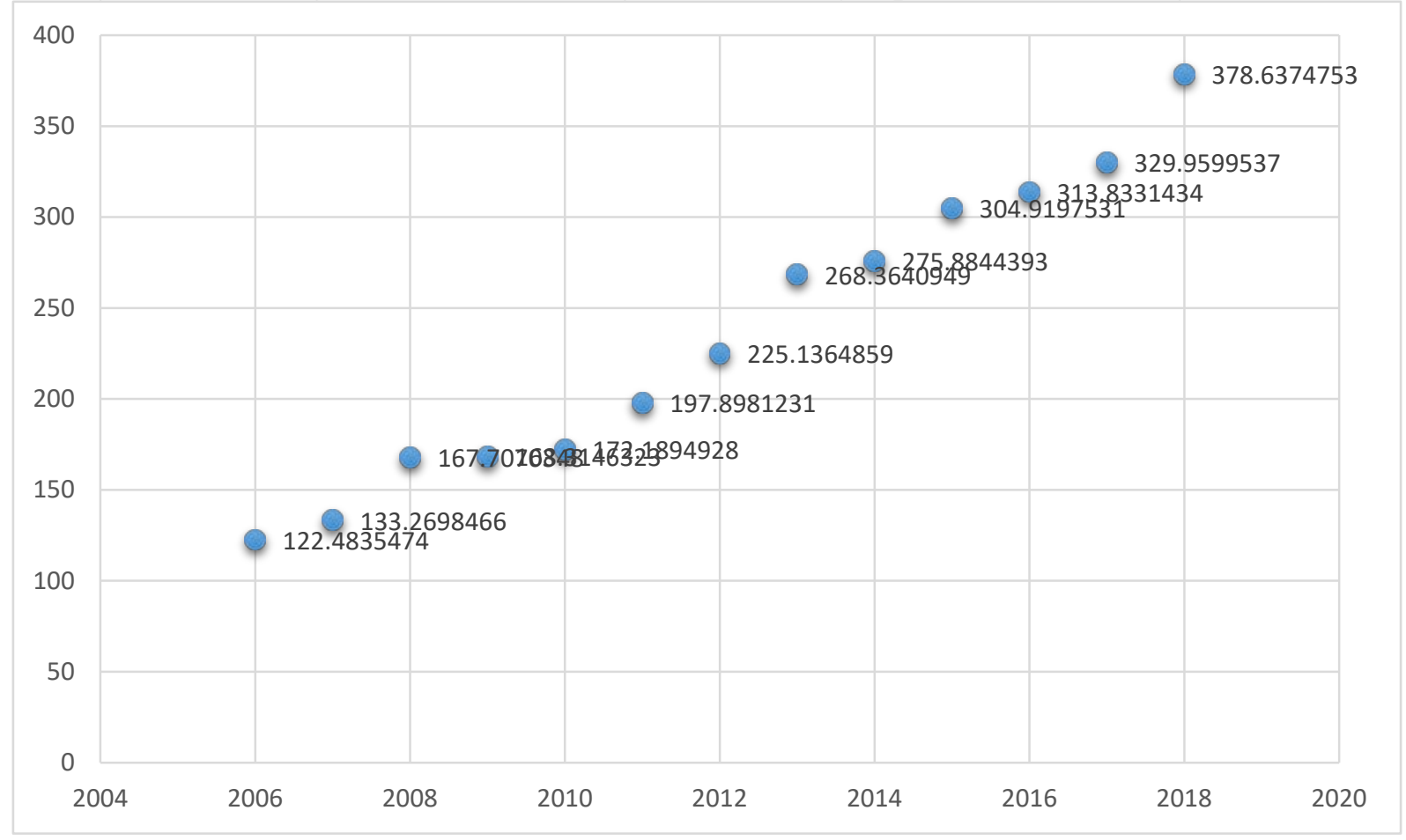

Figure 1 Growth of the number of fresh graduates in higher vocational colleges 
2.3. Establishing classroom teaching quality diagnosis and improvement mechanism is an effective means to guide classroom teaching to improve quality

Higher vocational colleges set up expert committees to diagnose the classroom teaching status, find the advantages and disadvantages of classroom teaching, point out the teacher's improvement direction and the key ability to be improved and promote teachers to continuously improve the quality of classroom teaching and help teachers to continuously improve teaching level. Ensure that the trained personnel meet the requirements of knowledge, ability and quality in the professional positions of the enterprise, give full play to the social service function of cultivating high-quality technical and skilled talents in higher vocational colleges and reflect the significance and value of the existence of higher vocational colleges.

\section{Quality Education Diagnosis and Improvement Mechanism Construction of Higher Vocational Colleges}

\subsection{Organizational guarantee}

Higher vocational colleges should set up a committee of classroom teaching quality diagnosis and improvement, comprehensively responsible for classroom teaching quality diagnosis and improvement planning and implementation and provide a strong organizational guarantee for the effective operation of diagnosis and improvement work. The specific contents include organizing high-level classroom teaching research, providing relevant policy consultation, formulating classroom teaching diagnosis work plan, guiding teachers, management departments and students to conduct multi-dimensional and multi-dimensional diagnosis activities and returning and returning to various types of diagnosis. Expert committees should also draw on industry experts, vocational education experts, education and teaching research experts, professors, supervisors, etc. to enhance the quality, level and level of the expert committee team ${ }^{[4]}$. The educational diagnosis program is mainly carried out from the following aspects, as shown in Figure 2.

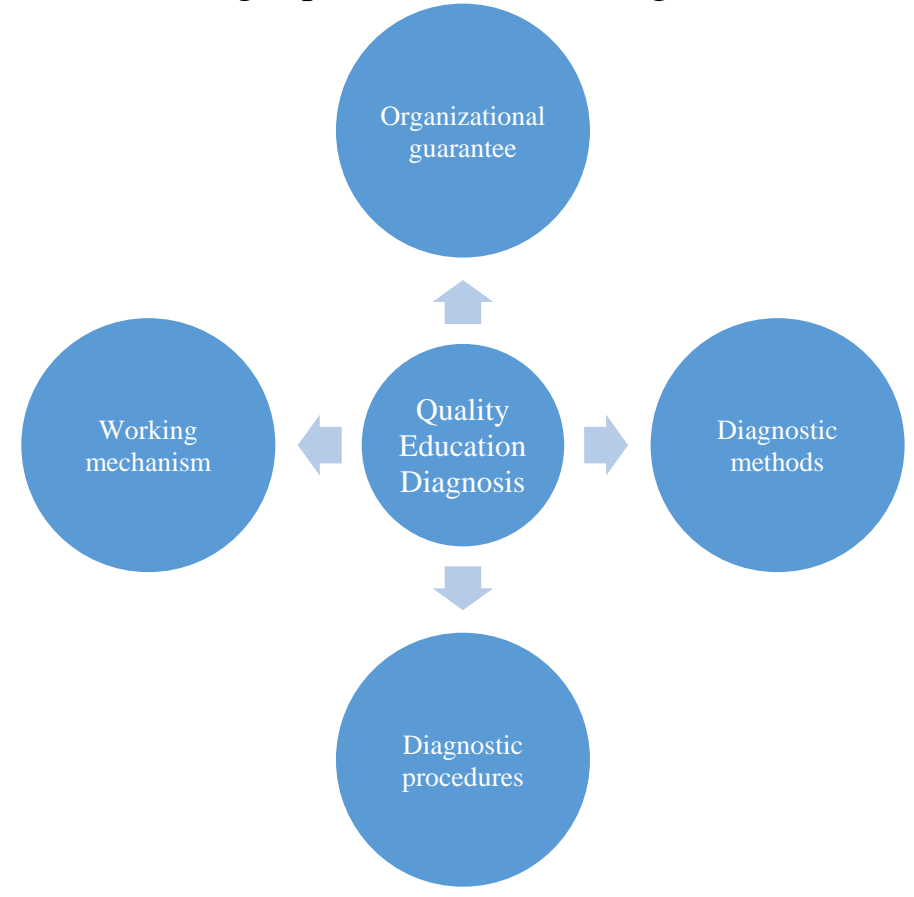

Figure 2 Educational diagnosis program 


\subsection{Working mechanism}

Higher vocational colleges should establish a normalized periodic classroom teaching diagnosis and improvement working mechanism based on self-diagnosis and external diagnosis. The intrinsic motivation is more durable. Therefore, the ultimate goal of classroom teaching diagnosis and improvement mechanism in higher vocational colleges is to establish a teacher self-diagnosis mechanism. Change the state of teachers' passive response to external pressures and motivate teachers to improve the enthusiasm and initiative of classroom teaching quality. The college should create an atmosphere and encourage teachers to make full use of the college's teaching quality management platform or self-designed questionnaires to initiate real-time evaluations for students, invite peers to evaluate their classroom teaching and give recommendations and actively submit diagnostic requirements to experts, periodically. Find problems - analyze problems - solve problems, find problems in classroom teaching, promptly improve according to feedback and suggestions and promote the continuous improvement of classroom teaching quality.

Higher vocational colleges establish classroom teaching diagnosis and improvement mechanisms and teachers' self-diagnosis should be supplemented by external diagnosis. Diagnosis and evaluation from the outside will inevitably create pressure to stimulate teachers to improve classroom teaching and enhance teaching skills, thus forcing teachers to make changes. External diagnostics include diagnoses performed by classroom quality diagnostics and improvement committee specialists, supervisory specialists, college administrators, students, or third-party organizations. After the external diagnosis is completed, a clear improvement plan should be given and the teacher should be instructed to make improvements. Diverse diagnostic results are conducive to teachers to form unique values in classroom teaching ${ }^{[5]}$.

\subsection{Diagnostic methods}

(1) Leading cadre listening system

Higher vocational colleges should establish and implement the system of leading cadres to listen to the lectures and require the leaders of the hospitals and functional departments to attend classes at least twice a semester. First, leading cadres attending classes form pressure and motivation for teachers to organize teaching. Second, after the lectures, the leading cadres propose suggestions for improvement to teachers and departments to help teachers improve their teaching.

(2) Teaching inspection

The teaching inspection work in higher vocational colleges is a routine teaching management work and a corresponding system has been formed, generally organized three times per semester. Teaching inspection is an important means to understand and master the teaching state. It can discover and solve problems in the teaching process in time to ensure the quality of classroom teaching. This long-established and functioning teaching management system still applies to the quality of classroom teaching. During the inspection, the organization's teaching management staff will give lectures to teachers' classroom teaching and ask for diagnosis opinions and improvement suggestions to help teachers reflect on teaching from multiple angles.

(3) Department diagnosis

The Department is responsible for the training and management of the teaching staff and shoulders the most direct responsibility for the quality of classroom teaching. The teaching ability of teachers' vocational education directly affects the development of the department. Therefore, the department should set up a diagnostic and improvement working group, develop a plan, organize lectures for teachers, teach and review and provide feedback and suggestions. 


\subsection{Diagnostic procedures}

Establish a database of teachers' teaching information. Use information technology to establish a historical archive for each teacher, including curriculum standard or syllabus, teaching plan, teaching log, lesson plans, student learning objectives, teaching activity records, diagnosis reports, feedback records, etc., improve the teaching information system and facilitate According to the collected teacher teaching information, analyze and study the teacher's classroom teaching situation and guide the teachers to continue to grow and develop. Develop a diagnostic work plan and design a diagnostic project based on the diagnostic content system. The expert committee organizes the classroom teaching diagnosis according to different methods. Recover diagnostic reports and suggestions for improvement, form a diagnostic report through analysis and research, feed back to the teacher and the department and regularly interview the teachers to discuss and improve the existing teaching.

\section{Conclusion}

The main purpose of diagnosis is not to evaluate performance, to evaluate and prioritize, but to encourage progress and promote growth. Investigate and study the classroom teaching situation, analyze the problems existing in the classroom teaching, feedback the diagnosis report and propose improvement suggestions. It should also guide, supervise and motivate the teachers to implement the improvement plan. How to improve? Choose the two most important elements to focus on and set goals for these issues at a certain stage, refine the final goals and develop them into daily and weekly content to ensure improved work results.

\section{References}

[1] Julia B. Frieze,Rajendra-Prasad Yadav,Khann Sokhan,Song Ngak,Team Bak Khim. Examining the quality of childhood tuberculosis diagnosis in Cambodia: a cross-sectional study[J]. BMC Public Health,2017,17(1).

[2] Tamás G,Abrantes C,Valadas A,Radics P,Albanese A,Tijssen M A J,Ferreira J J. Quality and reporting of guidelines on the diagnosis and management of dystonia.[J]. European journal of neurology,2017.

[3] Frieze Julia B,Yadav Rajendra-Prasad,Sokhan Khann,Ngak Song,Khim Team Bak. Examining the quality of childhood tuberculosis diagnosis in Cambodia: a cross-sectional study.[J]. BMC public health,2017,17(1).

[4] Alash'le Abimiku,Ralph Timperi,William Blattner. Laboratory Innovation Towards Quality Program Sustainability

[J]. Current HIV/AIDS Reports,2016,13(4).

[5]Abimiku Alash'le,Timperi Ralph,Blattner William. Laboratory Innovation Towards Quality Program Sustainability.[J]. Current HIV/AIDS reports,2016,13(4). 